\title{
Integrated Product Service Engineering - Factors Influencing Environmental Performance
}

\author{
Sofia Lingegård, Tomohiko Sakao* and Mattias Lindahl \\ Department of Management and Engineering, Linköping University \\ Sweden
}

\section{Introduction}

In society today there is increased awareness about environmental problems, e.g. climate change and pollution. This, in combination with concern about future shortages of natural resources, has resulted in increased pressure to find innovative strategies that can tackle these problems. Simply put, the main reasons for these problems are tied to society's use of products, and in general caused by:

- Number of products used - the growing population poses a need for an increasing number of products.

- $\quad$ Time products are used - the average time a product is used before it is scrapped has decreased. There are several reasons for this, e.g. quickly-changing needs and poor quality.

- How materials and energy are consumed for a product - in general, the material and energy invested for a product is not re-used or is used in an inefficient way.

Clearly, strategies for tackling these problems need to be investigated. During the last two decades, industry and academia have proposed and tried to implement several strategies and solutions. From academia, these include Functional Economy (Stahel 1994) and the Integrated Product Service Engineering (IPSE) concept, also often called Product/Service Systems (PSS) (e.g. (Mont 2002; Tukker and Tischner 2006; Sakao and Lindahl 2009)). PSS is defined, for instance, as "a marketable set of products and services capable of jointly fulfilling a user's needs" (Goedkoop, van Halen et al. 1999). Service in this chapter includes operation, maintenance, repair, upgrade, take-back, and consultation. In addition to this definition, other authors (Tukker and Tischner 2006) regard PSS as a value proposition, one including its network and infrastructure. Another concept, named Total Care Products (Functional Products), has been developed as well with some connection to PSS. It comprises "combinations of hardware and support services". The economically efficient functioning of this concept should be achieved by the proposition of an "intimate business relationship" between the service provider and the customer. As a result, both the provider and the customer obtain benefits through sharing existing business risks (Alonso-Rasgado, Thompson et al. 2004; Alonso-Rasgado and Thompson 2006). Furthermore, the proposal of a "life cycle-oriented design" (Aurich, Fuchs et al. 2006) highlights an important step for the

${ }^{*}$ Corresponding Author 
"product and technical service design processes" integration. It is also interesting that Aurich et al. address designing products and services based on life cycle thinking. Furthermore, some specific engineering procedures and computer tools have been developed and validated with industrial cases (e.g. (Sakao and Shimomura 2007; Sakao, Birkhofer et al. 2009; Sakao, Shimomura et al. 2009)).

However, the research in this area is still in its infancy and a number of questions remain unanswered. Specifically, a general weakness in existing literature is that even though a large number of authors have stressed PSS' environmental and economic potential (e.g. (Roy 2000; Mont, Singhal et al. 2006)), very few studies have proved PSS' potential for changing environmental performance.

In the manufacturing industry, the trend of servicizing has been evident regardless of the environmental concern or the academic debate (e.g. (Sakao, Napolitano et al. 2008)). In much of the manufacturing industry today, numerous companies' business offerings are a combination of physical products and services. In fact, over $50 \%$ of the companies in the USA and Finland provide both physical products and services (Neely 2007). Some manufacturing firms are even strategically shifting from being a "product seller" towards becoming a "service provider" (Oliva and Kallenberg 2003). Namely, the industry possesses a driver for service integration, something which should be seen as an interesting opportunity for academia (Isaksson, Larsson et al. 2009).

As explained above, PSS is a likely solution for environmental problems from the theoretical and practical viewpoints. However, little is known scientifically about PSS' impact on environmental performance. It is the research community who should respond to this lack of knowledge, and this is the overall subject of this chapter.

There are two main questions to consider. One is under which conditions PSS is a suitable offering, since it is a prerequisite for PSS to work in business practice in order to realize its influence on environmental performance. In general, PSS approaches seem to work well if any of the following conditions apply (Tukker and Tischner 2006):

- $\quad$ products with high costs to operate and/or maintain;

- complex products that require special competencies to design, operate, manage and/or maintain;

- products with considerable consequences or costs if not used correctly or appropriately;

- products where operational failure or downtime is not tolerated;

- products with long life; or

- $\quad$ products with only a few major customers on the market.

In addition, recent research has reported on characteristics of products suitable for PSS. For instance, (Lay, Copani et al. 2010) argue that the innovativeness of products has positive influences on the integration of product and service. Theoretical investigation has also begun: For instance, property rights (Furubotn and Pejovich 1972) have gained attention as a key for PSS to be meaningful (Hockerts 2008; Dill, Birkhofer et al. 2011). Yet, all these literature are insufficient, especially from scientific viewpoints.

The other main question is which PSS factors influence the environmental performance in comparison with traditional product-sales type business. (Tukker 2004) is one of very few who have attempted to analyze the relation between PSS types and their influence on environmental impact, yet he fails to present a thorough background and reasons. 
In sum, thus far there has been growing interest in PSS. Among other things, there has been relatively more work with the analytical approach (e.g. (Mont 2002)), and less work with PSS synthesis (e.g. (Sakao and Lindahl 2009)). Even with relatively more work available on analysis, there is analysis to be conducted as to PSS' factors making PSS meaningful as a business and influential on environmental impacts. This PSS with a certain level of complexity is believed to be a good example of areas where Systems Engineering (Lindemann 2011) can contribute.

\section{Objective and method}

This chapter endeavours to lead the scientific discussion regarding which IPSE factors are expected to, in theory, lower the environmental impact of a life cycle compared to a traditional product sales business. To do so, the IPSE concept is introduced, first with an emphasis on engineering processes rather than an object such as PSS. In the following sections, four aspects from theory will be discussed: product development, information asymmetry, economies of scale, and risk. These sections discuss how environmental impacts are influenced from a product life cycle perspective, and highlight crucial factors theoretically. They are followed by an overall discussion and an examination of some promising future work. The chapter provides the research community with a first theoretical cornerstone regarding environmental performance by IPSE. To practitioners, it will be an eye opener for how they engineer.

\section{Redefining IPSE}

Our research group at Linköping University and KTH (The Royal Institute of Technology) in Sweden has developed what is termed Integrated Product Service Engineering (IPSE) (Lindahl, Sundin et al. 2006). IPSE has the following characteristics in relation to other existing concepts. First, and in common with PSS, IPSE looks at combinations of products and services. Second, IPSE is a type of engineering, which is different from PSS per se. In addition, it attempts holistic optimization from the environmental and economic perspectives throughout the life cycle. Third, IPSE consists not only of design as the most influential activity, but possibly other engineering activities such as maintenance, upgrade, remanufacturing, etc. Therefore, IPSE has to deal with the time dimension of the life cycle. Figure 1 depicts different interesting processes for IPSE, obviously showing various disciplines and different aspects to be addressed.

This section reveals additional characteristics of IPSE. An IPSO (Integrated Product Service Offering) is an offering that consists of a combination of products and services that, based on a life cycle perspective, have been integrated to fit targeted customer needs. Further, IPSO means that products and services have been developed in parallel and are mutually adapted to operate well together. This contrasts with the traditional product sale, where the provider transfers control and responsibility to the customer at the point of sales. An IPSO often creates close contact between the supplier and customer, leading e.g. to offers being customized and improved to better suit the customer. In many cases, the service provider retains responsibility for the physical products in the IPSO during the use phase. One example is when a client does not own the machines installed by the supplier, but only uses them and pays for the manufactured volumes; then, when the customer does not need them anymore, the supplier takes back the machines. Such cases increase the provider's interest to 
ensure that the customer uses machines installed as long as possible and that any disturbances, such as the need for repairs, are reduced. The increased responsibility by the IPSO supplier also potentially facilitates improvements identified and implemented in comparison to traditional sales. This could lead to a product lifetime extension.

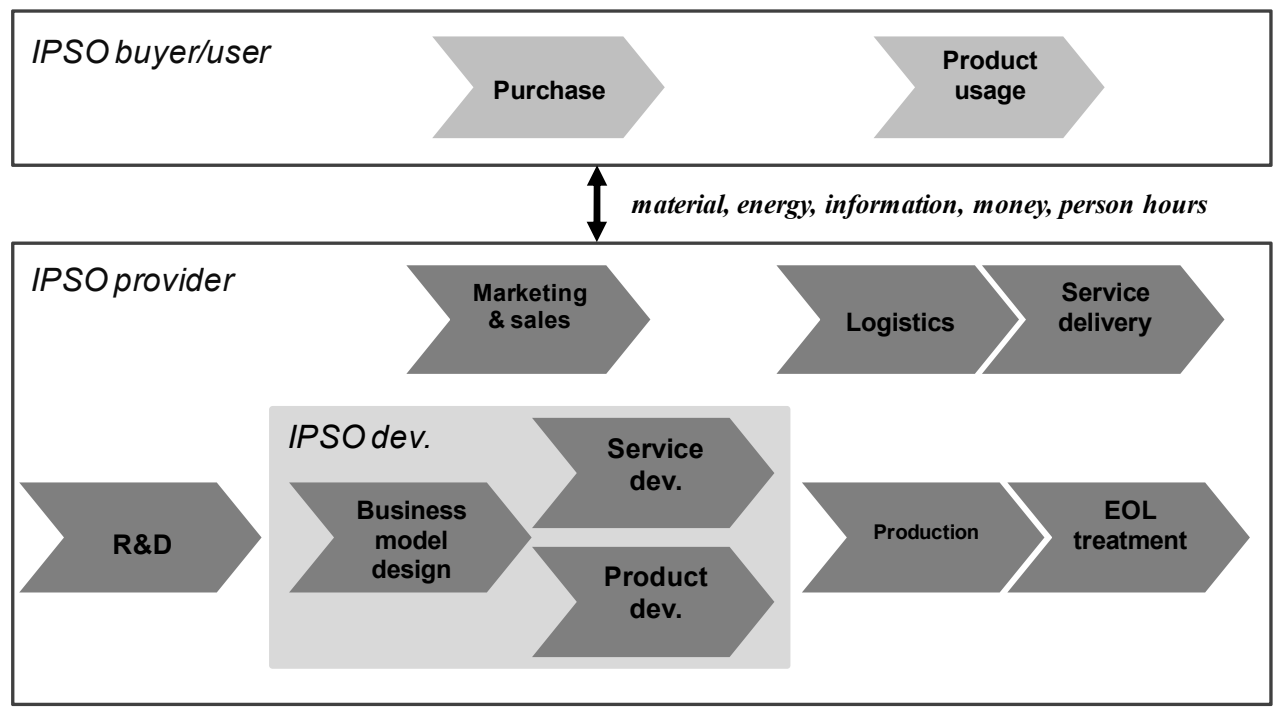

Note: IPSO; Integrated Product Service Offering. EOL; end of life.

Fig. 1. Processes of IPSE's interest (Sakao, Berggren et al. 2011)

Based on (Sakao 2009), IPSE is explained in comparison to Ecodesign (environmentally conscious design) due to some commonality with Figure 2 (a) and (b), where different types of engineering activities are put on the identical graph. The graph depicts the environmental impact of a certain type of product with high impact from its usage phase, which holds true in many cases. The horizontal axis represents the time dimension on the life cycle. Bars represent the environmental impact from each phase such as production and usage (scaled with the left vertical axis). A dotted line represents the accumulated influence of the activity at each phase of the life cycle's environmental impact. It is shown that the design phase has by far the highest ratio (some $80 \%$ ), which is generally known.

As seen by the dotted line, Ecodesign is obviously crucial, since it is the design activity with the dominant influence. However, is Ecodesign sufficient? The answer is no, since it leaves out control after the design phase. This is why IPSE is more effective, including the possible employment of other engineering activities such as maintenance. Naturally, company management must be committed if they are to carry out IPSE. IPSE includes a business issue, e.g. how to sell services.

What characteristics of IPSE are to be paid particular attention to in this chapter? The first is its length on the time dimension. It can be as long as 20 - 30 years in the case of an investment machine (e.g. aircraft engine) or facility (e.g. railway). Therefore, IPSE has to address much of this dimension with the fact that the earlier a certain action is taken the 
more effective its outcome is in general. It is actually realized by effective design. Thus, design is naturally a core of IPSE.

Then, what is design? A seminal work by (Pahl and Beitz 1996) states "design is an engineering activity that ... provides the prerequisites for the physical realization of solution ideas" (originally in (Martyrer 1960)). It has a lot to do with the processing of information information about needs and wants from stakeholders and through the product life cycle, as well as about function and structure of the product. Effective processing of information plays a central role in IPSE - this is the second characteristic.

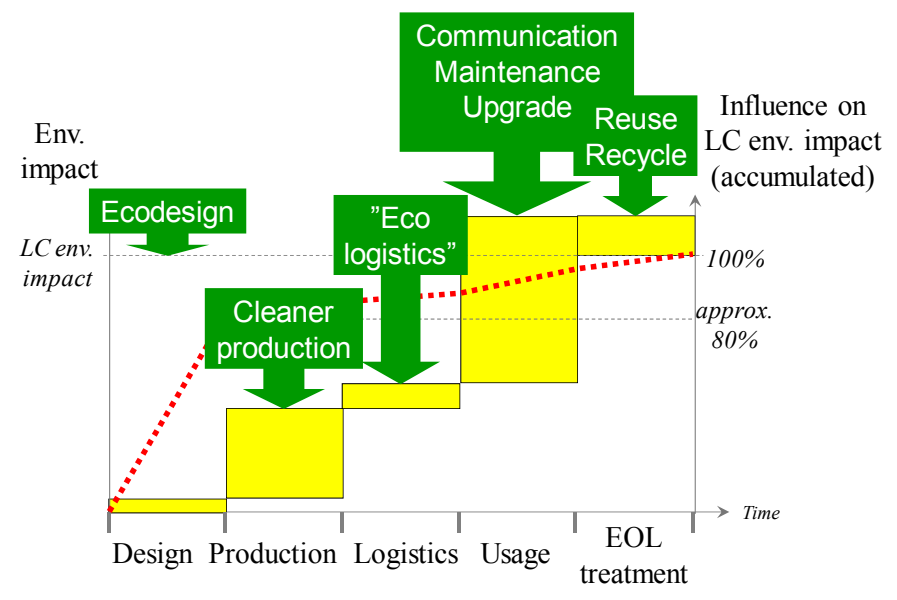

(a) Various Eco-activities

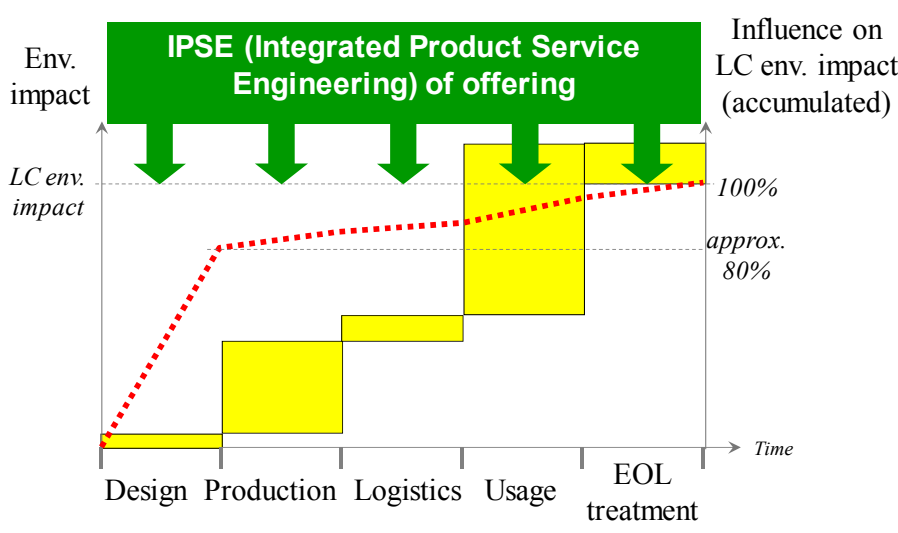

(b) IPSE

Note: The environmental impact (shown by bars) is a rough estimation of active products. EOL and LC stand for end-of-life and life cycle, respectively.

Fig. 2. Comparison of IPSE and other activities. 
Then, design of what? This is the next relevant question as discussed in (Cantamessa 2011), which points out an artefact, i.e. an object to be designed, is today "integrated and systemic product-services linked in a high-level user experience". Also acknowledging co-creation of value by a provider and a customer/user is a strong idea behind the servicizing (see e.g. (Vargo and Lusch 2004)), a provider cannot get rid of influence from its customer/user to create the intended value. Thus, a provider can design something contributing to its value, but cannot design the value itself. This means that control of risks of the value creation process is crucial. Thus, this risk is the third characteristics.

In sum, IPSE can be defined as an engineering activity controlling risks of value creation through dealing with information originating from a wide window on the time dimension. These three characteristics are discussed in the following sections with their relevant theories: time dimension and design with the theory of product development, information processing with theory about information asymmetry, and risk. In addition to these, economies of scale are also discussed since it is vital to business activities in general.

\section{Product development}

According to ENDREA† (ENDREA 2001), product development is defined as: "all activities in a company aiming at bringing a new product to the market. It normally involves design, marketing and manufacturing functions in the company". A product can in this context be both physical and non-physical. As is well known, when developing new products, designers typically follow a general procedure (sequence of activities), a so-called product development model. A product development model normally involves design, marketing and manufacturing activities. The current business model for many products, to get the customer to buy the product, implies that the focus is normally on cutting down the cost for manufacturing the product and delivering it to the customer. This is done in order to get a price that is accepted by the customer. It also implies that little focus is placed on later phases of the product's life cycle, e.g. the use phase (with activities such as use of energy and consumables, service and maintenance, and upgrading) and end-of-life. At the same time, life cycle cost studies and life cycle assessments have shown that for many products, it is during the use-phase (in reality often the longest phase of a product's life) and its related activities where the major costs and environmental impact for the product occur. Figure 2 shows, in a basic way (different products have different profiles), the environmental impact accumulation over the product's life cycle.

When developing IPSO, the basic principal is to consider all life cycle phases in order to optimize the offering from a life cycle perspective. The idea is to get the lowest total cost for the offering possible, not only to get the lowest cost for product. This generates new conditions for the product development. Since the focus is expanded to cover more life cycle phases, e.g. the use phase, it implies that the number of potential offering solutions

\footnotetext{
† Engineering Research and Education Agenda (ENDREA). ENDREA was a joint effort between four of the major Swedish institutes of technology: Chalmers University of Technology in Göteborg, the Royal Institute of Technology in Stockholm, Linköping Institute of Technology in Linköping and Luleå University of Technology in Luleå. Funding came from the Swedish board for strategic research, SSF, industry and the participating universities. The main idea behind ENDREA was to create a national cooperation in creating a new type of research in the engineering design area.
} 
increases, which is good from an optimizing perspective. At the same time, costs are often associated with the use of materials and energy, which in turn provides a negative environmental impact, implying that more cost-optimized products usually have less environmental impact.

Figure 2 also illustrates the different phase's impact on the total environmental impact and how important the design phase is, especially the early part of it. This is at the same time logical, since it is in the early phases of product development that the product specification is defined, i.e. what parameters must/should be focused on. Examples of parameters are: how it will be used; how long it will work; what type of power it will use; what type and amount of consumables will be used during the normal use phase; what spare parts will be needed; and what is the lifetime of the product. Today, many companies' main concern in their product specifications is how to optimize and improve the production of their products, and how to develop products that are not too durable. This is important, since the predominate way of earning money is by selling products to customers.

At the same time, the initial product specification sets up boundaries for potential actions in the later phases. This is a well-known fact for people working with product development, often referred to as the "design paradox". When a new design project starts, very little is known about the final product, especially if the product is a new one for the designers. As the work on the product progresses, knowledge is increased. At the same time, the scope of freedom of action decreases for every product decision step taken, since time and cost drive most projects. Costs for later changes increase rapidly, since earlier work must be redone (Ullman 2002). The paradox is that when the general design information is needed, it is not accessible, and when it is accessible, the information is usually not needed.

Figure 3 shows the principal relation between freedom of action, product knowledge and modification cost $\ddagger$. The figure is the author's further development of three figures: the design paradox (Ullman 2002), costs allocated early but used late in the project (Andreasen 1987) and the cost for design changes as a function of time during the planning and production process (Bergman and Klefsjö 2003).

Figures 2 and 3 illustrate the importance of the design phase as well as getting in relevant requirements as early as possible in the development process. It also shows the problem with traditional product development. Often, little care is taken in product development (and in its specification) for future services, maintenance, and end-of-life-treatment. Traditionally, the initial focus is on developing the physical product; once that is done, a possible service (intangible product) is developed, but this is hindered by the limitations set up from the physical product. When developing IPSO, the development is accomplished in an integrated and parallel approach.

The rate of market and technological changes has accelerated in the past decade. This implies that companies must be pro-active in the sense that they must be able to rapidly respond to fluctuations in demand (Collaine, Lutz et al. 2002). Central to competitive success in the present highly-turbulent environment is: the company's capability to develop new products (Gonzalez and Palacios 2002); to improve, further develop and optimize old

₹ This figure can also be found in the author's licentiate thesis Lindahl, M. (2000). Environmental Effect Analysis - an approach to design for environment Licentiate Thesis, Royal Institute of Technology. 
products; and to do so faster than competitors (Stalk and Hout 1990). Designers must develop and proceed faster, while at the same time covering an increased number of different demands on the product. A way to handle these challenges is to do more of the product development in a more parallel and concurrent way in order to e.g. shorten the calendar time (from start to stop) and increase the collaboration over competence disciplines. One concept in line with this is Integrated Product Development $\$$ (IPD), whose basic idea is to increase the efficiency in product development by more parallel activities and a higher degree of co-operation between functions, levels and individuals in an enterprise (Olsson 1976; Andreasen 1980). Norell (1999) characterizes the performance of IPD as follows: parallel activities; cross-functional collaboration by multifunctional teams; structured processes; and front-loaded development. The four characteristics above are in line with what (Wheelwright and Clark 1992), (Cooper, Edgett et al. 1998), and (Wilson, Kennedy et al. 1995) regard as important features for successful product development.

However, if a business model is changed from selling products to providing a function via IPSO, this also changes the conditions for development. When selling products, there is a need to constantly sell new ones in order to survive. In order to do so, the company must constantly come out with new models and/or features, and do so at an increased speed to keep competitors out. This also implies that a company should not want to offer all potential technical improvements in new products, but rather split them up over several versions in order to be able to sell more products over time.

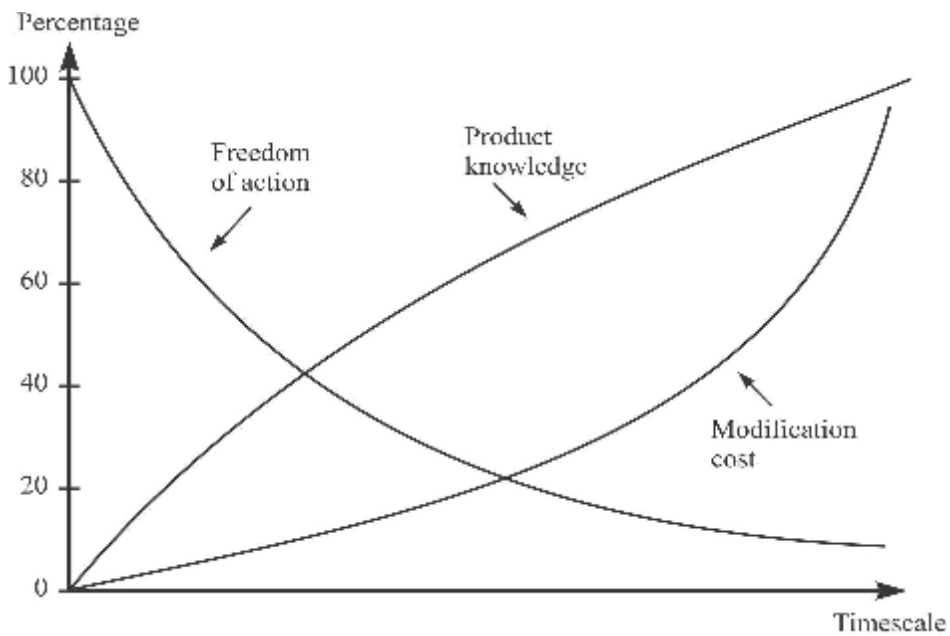

Fig. 3. The relation between "Freedom of action", "Product knowledge" and "Modification cost" is shown (Lindahl and Tingström 2000).

However, if a company sells IPSO, this is changed since the focus is not on selling products but rather on selling functionality to the customer. In principal, once an IPSO is sold to a customer, the company wants him/her to use it for as long a time as it is economically

$\S$ Other similar common terms which correspond to this concept are Concurrent Engineering (Söderved, 1991), (Prasad, 1997) and Lean Product Development (Mynott, 2001). 
interesting. If a company has technology that can e.g. cut down the energy consumption during use, it will implement the best technique at once instead of taking it in steps. Instead of spending time on developing different versions of a product, with IPSO the company in principal has more time for developing more optimized offerings - offerings that are more cost-efficient and effective, and therefore in general give a lower negative environmental impact. Nevertheless, it will still be relevant for shortening the calendar time (from start to stop).

\section{Information asymmetric between a provider and a user}

In general, environmental impact of a product life cycle is determined by product characteristics themselves and processes on the product. The former includes the type and amount of materials in a product, while the latter includes how to treat the product at EOL (end of life). Thus, the environmental impact of a product can be decreased by changing either its characteristics or its processes. However, one has to own and apply appropriate information to do so. There are different types of such information about a product itself or processes along the life cycle phases such as design, manufacturing, usage, and EOL. In addition, the information may not be documented in such a way that it is easily transferrable to another actor as depicted in Figure 4.

Who owns the information on how to improve the environmental aspect of the product and processes at different stages of the life cycle? Information asymmetry exists in many cases between the OEM, who in many cases designs a product, and the user. For instance, how the substances contained in a product are toxic is not necessarily known to a user but is to a designer. In addition, how to attain the best energy performance for the product in practice may be more hidden to a user than to a designer - the user simply does not know how to operate the given product for the best performance, or the provider has more knowledge of the best available technologies at the moment. There can be various reasons for this, such as a lack of user education in spite of the existence of the necessary information, or the strategy of a user as a company not to get the competence.

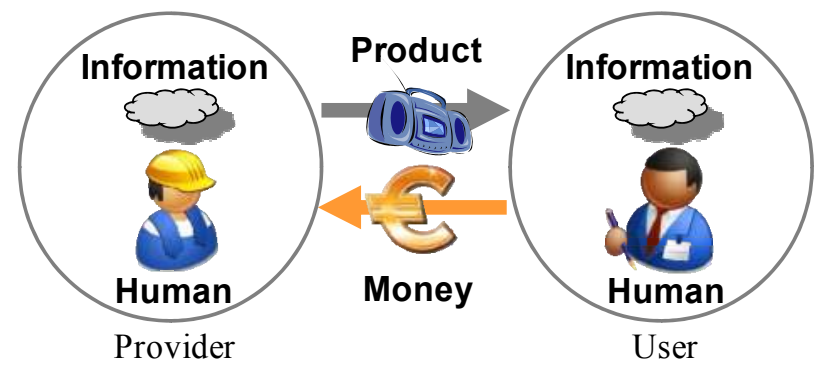

Fig. 4. General illustration of information owned by provider and user

Note that information asymmetry in the "market for lemons" addressed by (Akerlof 1970) is not the main issue of this chapter. In that case, the information possessed by a provider is about a product at a point of sale and is unchanged after the sale of the product, as it is based on a product-sales type business and the provider has no access to the product afterwards. This is shown with gray lines in Figure 5: the information of a user about the 
product increases along time and can surpass that of a provider. Note that variation of speed of the increase along time is not considered in this graph. In IPSE, on the other hand, a provider can obtain more information with access to the product during usage, and could maintain superiority regarding product information over the user. This is drawn as Cases 1 and 2 in Figure 5, to refer to the same and a higher speed as compared to the user, respectively. In Case 3, due to the lower speed than the user, the provider is surpassed by the user.

Information asymmetry can be a weapon for a provider to obtain payment in IPSE and makes IPSE meaningful as a business. For example, in the case where an OEM owns more information about usage or EOL of a product, there is potential for the OEM to provide IPSO so that the environmental impact is less than would be for product sales. It is also often reasonable for an OEM to be able to provide maintenance or upgrade service of its product. From the viewpoint of environmental performance, on the other hand, information asymmetry is a hindrance to improvement, since it is costly to transfer information to an actor who needs it.

Some regulations are effective so as to diminish the information asymmetry - a simple example is a symbol of "no to be put it in a dustbin" attached to an electronic product by the WEEE (Waste Electrical and Electronic Equipment Directive) (EU 2003). This symbol conveys effective information from a provider to a user: this product should not be disposed of in a regular dustbin from an environmental viewpoint. As is explained by Cerin (Cerin 2006), this type of information flow has potential to decrease the environmental impact. However, everything is not covered by regulations. A user may be willing to pay for information that contributes to the environmental performance of the product. This is where business opportunities for an OEM as an IPSO provider can be found.

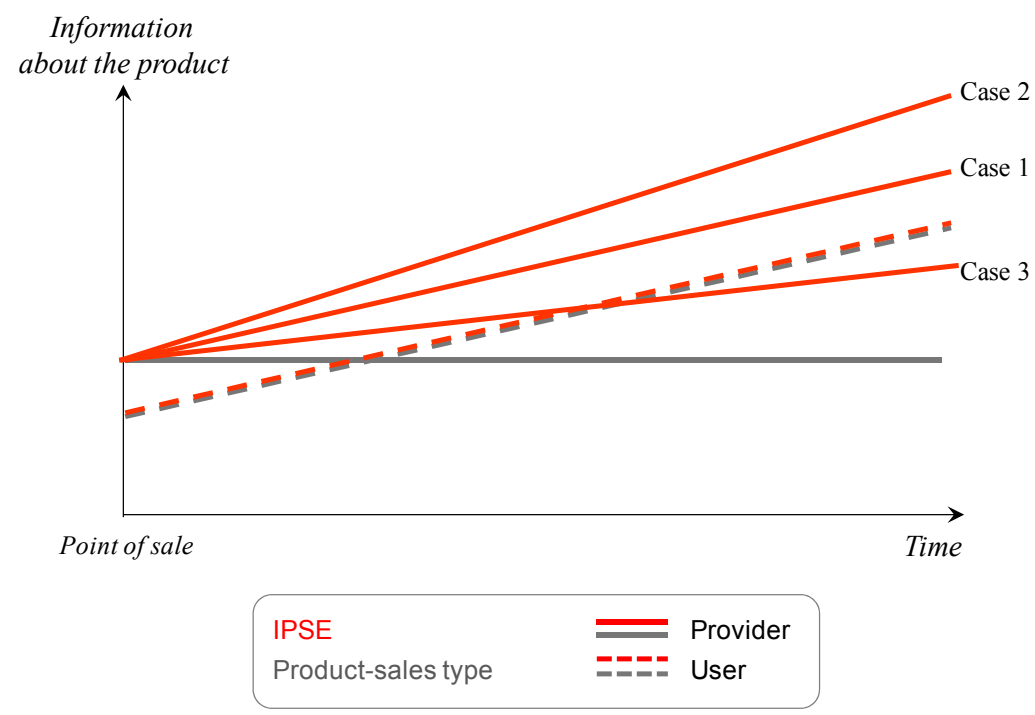

Fig. 5. Transitions of amount of information about a product after sales 
Summarizing the discussion above, three levels of information asymmetry are assumed to exist in this context. If there is no (or too little) information asymmetry, there will be no gain in environmental performance through IPSE and no IPSE activities. On the other hand, in case there is a high level of information asymmetry, i.e. enough to make IPSE meaningful, there would be economic activities as well as environmental gain. The rest is an intermediate level, where there are no IPSE activities and thus loss of environmental performance. Note that this discussion focuses on a single parameter, information asymmetry; there can be other influential parameters if IPSE is meaningful.

\section{Economies of scale}

Economies of scale are the result of an increased number of units produced or distributed, making it possible for the unit price to decrease (Chandler 2001; Cook, Bhamra et al. 2006). An IPSE provider has the possibility to attain economies of scale through several different aspects. To provide IPSE is, in some cases, equal to being responsible for all the life cycle costs of the offering, which provide incentives to optimize the total cost as well as to realize economic development, and potentially environmental development (Lindahl, Sundin et al. 2006; Tukker and Tischner 2006). The provider would be able to gain economies of scale for both the products and the services. Leverage in production and administration could be created by offering the same services to different customers (Morey and Pacheco 2003). Another way of decreasing costs and achieving economies of scale could be realized when answering customers' demands by constantly configuring the same technology and skills in different ways (Cook, Bhamra et al. 2006). For a certain industry the market capacity is limited, which means that a single company may not reach its scale of economy since its market share is relatively fixed for a certain period of time. It is not possible to realize largescale effects with only a few customers, since much information is needed before, during and after the delivery which results in high transaction costs (Arnold 2000). If a number of companies outsourced their processes to one organization, this would aggregate the volume and the production efficiency would increase (Gao, Yao et al. 2009). This would also bring down the transaction costs, since they were created when transferring goods and services (Chandler 2001). If the transactions occur frequently they are better handled within one single organization, since hierarchical governance facilitates administrative control and coordinated adaptability (Toffel 2008). Furthermore, customers want to benefit from the knowledge of the supplier, and are reluctant to do business with several suppliers if they want an integrated and global offering (Mathieu 2001). However, the number of actors should be enough to make sure all the components of the offer are delivered by experts (Mont 2004).

Reduced transaction costs are not the only costs to consider. New costs for complementary products may also appear for the provider in the beginning, but will benefit from economies of scale after the transition (Toffel 2008). Even though IPSE offerings imply customized solutions to achieve economies of scale, they have to be combined with well-defined modular structures at the component level (Windahl, Andersson et al. 2004). If a company wants to profit from economies of scale, this standardization of components is to be the first step (Arnold 2000). This could also be useful when considering remanufacturing, since parts that are worn out quickly or 
require frequent upgrading should be placed in an accessible way (Sundin and Bras 2005). Considering the remanufacturing, this process could also benefit from an economies of scale perspective. The IPSE approach would provide the manufacturer with the knowledge of how many products that are entering the process, as well as when they would do so, which would provide the IPSE provider with a remanufacturing plan that is easier to manage (Sundin and Bras 2005).

When it comes to other steps in the life cycle of the offering, the IPSE provider can economically afford a high level of specialization and technological features due to economies of scale, and can thereby optimize resource consumption and waste production, leading to better eco-efficiency for the company. The provider also often gains a competitive advantage over the customer when it comes to experience and knowledge concerning the product. With this information, the provider can optimize maintenance routines and thereby minimize the cost (Toffel 2008). Furthermore, the provider can benefit from scale effects when observing how the equipment is repaired across their whole customer base and use this knowledge (Toffel 2008). Further increased knowledge and understanding will result in increased availability and reduced product failures (Alonso-Rasgado, Thompson et al. 2004). Economies of scale can also emerge when the provider is in charge of the operations at the site of the customer, when the expertise of the provider in running the equipment can provide reduction in lead time and scale affects (Lay, Schroeter et al. 2009).

In sum, there are economies of scale in IPSE as well. Major positive factors include carrying out similar services so that an organization can learn from one service and apply it to another. In the case of IPSE, in contrast to the case of selling physical products, exactly the same offering does not exist, since a customer or user is involved in the service. This difference means that IPSE requires more involvement of staffs of a provider learning to gain economies of scale. Another factor is a market capacity, and it is necessary to take into account transaction cost and complementary product cost. Needs addressed by IPSE differ slightly from one offering to another. Therefore, modularization is a key to gain economies of scale, but service modularization needs more research than product modularization (e.g. (Simpson, Siddique et al. 2006)).

\section{Risk}

There are various types of risk, namely possible negative consequences from the environmental viewpoint. Reasons for this include an actor's lack of necessary information due to another actor's possession of the information, which was already discussed in the section on information asymmetry. There is another reason as well - non-existence of information.

Whether a product is better from an environmental standpoint for a given need is not necessarily certain at the time the product is first used. Different factors for this originate from the environment (not in the meaning of sustainability) and users. The former includes the speed of progress of the technology used in the product (or product generations) (see e.g. (Deng and Williams 2011)). If a new product is more energy efficient than the original one, and it becomes available before the end of usage, it may be better 
environmentally to switch to the new product. The user factor includes his/her discontinuity with the need for the chosen product (see different classical reasons for this in (Hanson 1980)). For instance, a change in demand causing a user to stop using a product after a short time, and owning another product in addition, generates additional environmental impact.

How can these different types of uncertainty be better handled? A provider could do this. If a provider promises a user in a contract that the "best" available technology is provided within the contract period, the user can avoid the uncertainty of the technology progress. For the user's discontinuity of the need, a provider could give an option to a user so that the user can return the product to the provider after a certain period of time. By doing so, a user can shorten the time of holding that risk. The "trick" behind this is scale of economy that enables a provider to cancel different types of risks arising from its users. Thus, variety of the needs by a group of many customers is cancelled.

In sum, there are different types of uncertainty, due to unavailable information. In the case of product sales, they generate risks of producing higher environmental impact than if this uncertainty and risk is managed through IPSE. Note that this is not merely an actor's lack of information; rather, the information is not available in spite of a willingness to get it. This is where business opportunities for IPSO exist, and existing research has not approached with that viewpoint. For instance, uncertainty in PSS has been researched as an object to be reduced for more accurate cost estimation (Erkoyuncu, Roy et al. 2011). Note that e.g. leasing by itself does not improve EOL management of leased products (Lifset and Lindhqvist 1999). If there is a high degree of uncertainty of technological progress or demand discontinuity, and if the risk can be cancelled by an OEM, IPSO has potential to decrease environmental impact.

\section{Concluding discussion}

This chapter endeavoured to lead theoretical discussion regarding which IPSE factors are expected to increase environmental performance of a life cycle compared to a traditional product sales business. Four aspects from theory were discussed and their relevance was pointed out. In the theory of product development, information about a product is pointed out to be a crucial parameter, although the theory is to be adapted according to the nature of the offering - IPSO as opposed to a physical, traditional product. Then, asymmetry of the information about a product between a provider and a user was identified as a key for IPSE to be meaningful also through comparison with the product sales type business. Economies of scale were brought into the discussion and this remains to be an important issue for IPSE but with different characteristics from the product sales type business. Finally, risk was discussed and pointed out to be a crucial parameter to be controlled after sale and economies of scale were shown to be an enabler to control the risk in a better way. As shown in these four sections, these aspects are interlinked with each other (see Figure 6) and need to be further investigated. Nevertheless, the chapter has provided a first theoretical cornerstone regarding conditions for IPSE to be a meaningful business style and IPSE's influential factors on environmental performance. 


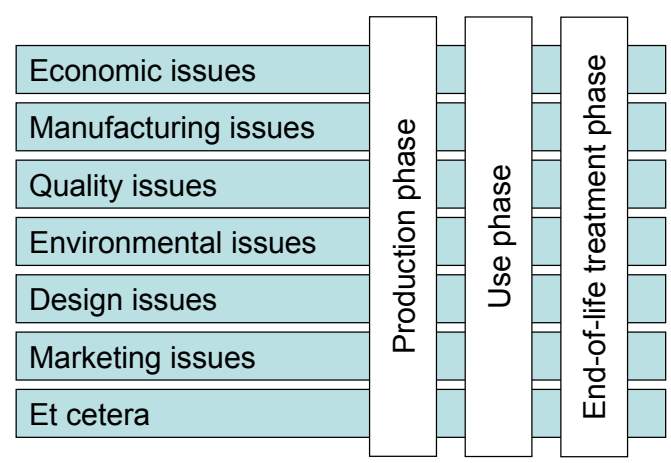

Fig. 6. Relations between different issues at each phase of a life cycle

\section{Acknowledgment}

This research was partially supported by a Trafikverket (the Swedish Transport Administration)-funded project "Integrated Product Service Offerings of the Railway Infrastructure System".

\section{References}

Akerlof, G. (1970). "The market for lemons: quality uncertainty and the market mechanism." Quarterly Journal of Economics 84: 488-500.

Alonso-Rasgado, T. and G. Thompson (2006). "A rapid design process for Total Care Product creation." Journal of Engineering Design 17(6): 509 - 531.

Alonso-Rasgado, T., G. Thompson, et al. (2004). "The design of functional (total care) products." Journal of Engineering Design 15(6): 515-540.

Andreasen, M. (1987). Integrated Product Development. Berlin, Springer.

Andreasen, M. M. (1980). Machine Design Methods Based on a Systematic Approach. Lund, University of Lund. Ph.D. Thesis.

Arnold, U. (2000). "New dimensions of outsourcing: a combination of transaction cost economics and the core competencies concept." European Journal of Purchasing \& Supply Management 6(1): 23-29.

Aurich, J. C., C. Fuchs, et al. (2006). "Life cycle oriented design of technical Product-Service Systems." Journal of Cleaner Production 14(17): 1480-1494.

Bergman, B. and B. Klefsjö (2003). Quality from Customer Needs to Customer Satisfaction. Lund, Studentlitteratur AB.

Cantamessa, M. (2011). Design ... but of What. The Future of Design Methodology. H. Birkhofer. London, Springer: 229-237.

Cerin, P. (2006). "Bringing economic opportunity into line with environmental influence: A discussion on the Coase theorem and the Porter and van der Linde hypothesis." Ecological Economics 56 209- 225. 
Chandler, A. D. (2001). Scale and Scope: The Dynamics of Industrial Capitalism. Cambridge, The Belknap Press of Harvard University Press.

Collaine, A., P. Lutz, et al. (2002). "A method for assessing the impact of product development on the company." International Journal of Production Research 40(14): 3311 - 3336.

Cook, M. B., T. A. Bhamra, et al. (2006). "The transfer and application of Product Service Systems: from academia to UK manufacturing firms." Journal of Cleaner Production 14(17): 1455-1465

Cooper, R. G., S. J. Edgett, et al. (1998). Portfolio Management for New Products. Reading, MA, Perseus Books.

Deng, L. and E. D. Williams (2011). "Functionality Versus 'Typical Product' Measures of Technological Progress." Journal of Industrial Ecology 15(1): 108-121.

Dill, A. K., H. Birkhofer, et al. (2011). Property Rights Theory as a Key Aspect in Product Service Engineering. International Conference on Engineering Design, Copenhagen.

ENDREA (2001). ENDREA nomenclature. Linköping, ENDREA - Engineering Research and Education Agenda.

Erkoyuncu, J. A., R. Roy, et al. (2011). "Understanding service uncertainties in Industrial Product-Service System cost estimation." International Journal of Advanced Manufacturing Technology 52(9-12): 1223-1238.

EU (2003). "Directive 2002/96/EC of the European Parliament and of the Council of 27 January 2003 on waste electrical and electronic equipment (WEEE)." Official Journal of the European Union L 37: 24-39.

Furubotn, E. G. and S. Pejovich (1972). "Property Rights and Economic Theory: A Survey of Recent Literature." Journal of Economic Literature 10: 1137-1162.

Gao, J., Y. Yao, et al. (2009). "Service-oriented manufacturing: a new product pattern and manufacturing paradigm." Journal Intelligent Manufacturing 22(3): 435-446.

Goedkoop, M. J., C. J. van Halen, et al. (1999). Product Service Systems, Ecological and Economic Basics. Hague, Dutch Ministry of Housing, Spatial Planning and the Environment.

Gonzalez, F. J. M. and T. M. B. Palacios (2002). "The effect of new product development techniques on new product success in Spanish firms." Industrial Marketing Management 31(3): 261-271.

Hanson, J. (1980). "A proposed paradigm for consumer product disposition processes." Journal of Consumer Affairs 14: 49-67.

Hockerts, K. (2008). Property Rights as a Predictor for Eco-Efficiency of Product-Service Systems. CBS Working Paper Series. Frederiksberg, Copenhagen Business School.

Isaksson, O., T. C. Larsson, et al. (2009). "Development of product-service systems: challenges and opportunities for the manufacturing firm." Journal of Engineering Design 20(4): 329 - 348.

Lay, G., G. Copani, et al. (2010). "The relevance of service in European manufacturing industries." Journal of Service Management 21(5): 715-726. 
Lay, G., M. Schroeter, et al. (2009). "Service-Based Business Concepts: A Typology for Business-to-Business Markets." European Management Journal 27(6): 442-455.

Lifset, R. and T. Lindhqvist (1999). "Does Leasing Improve End of Product Life Management?" Journal of Industrial Ecology 3(4): 10-13.

Lindahl, M., E. Sundin, et al. (2006). Integrated Product and Service Engineering - the IPSE project. Changes to Sustainable Consumption, Workshop of the Sustainable Consumption Research Exchange (SCORE!) Network, supported by the EU's 6th Framework Programme, Copenhagen, Denmark.

Lindahl, M. and J. Tingström (2000). A Small Textbook on Environmental Effect Analysis. Kalmar, Department of Technology, University of Kalmar.

Lindemann, U. (2011). Systems Engineering versus Design Methodology. The Future of Design Methodology. H. Birkhofer. London, Springer: 157-167.

Martyrer, E. (1960). "Der Ingenieur und das Konstruieren." Konstruktion 12: 1-4.

Mathieu, V. (2001). "Service strategies within the manufacturing sector: benefits, costs and partnership." Intermational Journal of Service Industry Management 12(5): 451475.

Mont, O. (2004). "Institutionalisation of sustainable consumption patterns based on shared use." Ecological Economics 50(1-2): 135-153.

Mont, O., P. Singhal, et al. (2006). "Chemical Management Services in Sweden and Europe: Lessons for the Future." Journal of Industrial Ecology 10(1/2): 279-292.

Mont, O. K. (2002). "Clarifying the concept of product-service system." Journal of Cleaner Production 10(3): 237-245.

Morey, E. and D. Pacheco (2003). "Prouct service systems: Exploring the potential for economic and environmental efficiency."

Mynott, C. (2001). Lean product development: the manager's guide to organising, running and controlling the complete business process of developing products. Northampton, UK, Westfield Publ.

Neely, A. (2007). The servitization of manufacturing: an analysis of global trends. 14th EurOMA Conference, Ankara.

Oliva, R. and R. Kallenberg (2003). "Managing the transition from products to services." International Journal of Service Industry Management 14(2): 160-172.

Olsson, F. (1976). Systematic Design. Lund, University of Lund. Doctoral Thesis.

Pahl, G. and W. Beitz (1996). Engineering Design: A Systematic Approach. London, Springer-Verlag: 1.

Prasad, B. (1997). Concurrent Engineering Fundamentals - Integrated Product Development - Volume 2. Upper Saddle River, New Jersey, Prentice-Hall.

Roy, R. (2000). "Sustainable product-service systems." Futures 32: 289-299.

Sakao, T. (2009). A View of Service, Quality, and Value for Sustainability. 12th International QMOD Conference, Verona.

Sakao, T., C. Berggren, et al. (2011). Research on Services in the Manufacturing Industry based on a Holistic Viewpoint and Interdisciplinary Approach. CIRP International Conference on Industrial Product-Service Systems, Braunschweig. 
Sakao, T., H. Birkhofer, et al. (2009). "An Effective and Efficient Method to Design Services: Empirical Study for Services by an Investment-machine Manufacturer." International Journal of Internet Manufacturing and Services 2(1): 95-110.

Sakao, T. and M. Lindahl, Eds. (2009). Introduction to Product/Service-System Design. Springer's global publishing programme in engineering and management. London, Springer.

Söderved, H. (1991). Concurrent Engineering - ett arbetssätt för effektiv produktframtagning (in Swedish only). Stockholm, Sveriges Mekanförbund.

Sakao, T., N. Napolitano, et al. (2008). "How Are Product-Service Combined Offers Provided in Germany and Italy? - Analysis with Company Sizes and Countries -." Journal of Systems Science and Systems Engineering 17(3): 367-381.

Sakao, T. and Y. Shimomura (2007). "Service Engineering: A Novel Engineering Discipline for Producers to Increase Value Combining Service and Product." Journal of Cleaner Production 15(6): 590-604.

Sakao, T., Y. Shimomura, et al. (2009). "Modeling Design Objects in CAD System for Service/Product Engineering." Computer-Aided Design 41(3): 197-213.

Simpson, T. W., Z. Siddique, et al. (2006). Product Platform and Product Family Design: Methods and Applications. New York, Springer.

Stahel, W. R. (1994). The Utilization-Focused Service Economy: Resource Efficiency and Product-Life Extension. The Greening of Industrial Ecosystems. Washinton DC, National Academy Press: 178-190.

Stalk, G. J. and T. M. Hout (1990). Competing Against Time - How Time-Based Competition is Reshaping the Global Markets. New York, The Free Press, A Division of Macmillan Inc.

Sundin, E. and B. Bras (2005). "Making functional sales environmentally and economically beneficial through product remanufacturing." Journal of Cleaner Production 13(9): 913-925.

Toffel, W. M. (2008). Contracting for Servicizing.

Tukker, A. (2004). "Eight Types of Product-Service System: Eight Ways to Sustainability? Experiences from Suspronet." Business Strategy and the Environment 13: 246 260.

Tukker, A. and U. Tischner (2006). New Business for Old Europe. Sheffield, Greenleaf Publishing.

Ullman, D., G. (2002). The Mechanical Design Process. New York, McGraw-Hill Higher Education.

Vargo, S. L. and R. F. Lusch (2004). "Evolving to a New Dominant Logic for Marketing." Journal of Marketing 68(1): 1-17.

Wheelwright, S. C. and K. B. Clark (1992). Revolutionizing Product Development: Quantum Leaps in Speed, Efficiency, and Quality. New York, Free Press.

Wilson, C. C., M. E. Kennedy, et al. (1995). Superior Product Development: Managing the Process for Innovative Products: A Product Management Book for Engineering and Business Professionals, Blackwell Publishers. 
Windahl, C., P. Andersson, et al. (2004). "Manufacturing firms and integrated solutions: characteristics and implications " European Journal of Innovation Management 7(3): 218-228. 


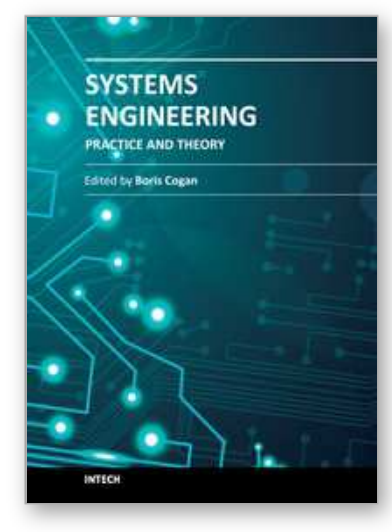

\author{
Systems Engineering - Practice and Theory \\ Edited by Prof. Boris Cogan
}

ISBN 978-953-51-0322-6

Hard cover, 354 pages

Publisher InTech

Published online 16, March, 2012

Published in print edition March, 2012

The book "Systems Engineering: Practice and Theory" is a collection of articles written by developers and researches from all around the globe. Mostly they present methodologies for separate Systems Engineering processes; others consider issues of adjacent knowledge areas and sub-areas that significantly contribute to systems development, operation, and maintenance. Case studies include aircraft, spacecrafts, and space systems development, post-analysis of data collected during operation of large systems etc. Important issues related to "bottlenecks" of Systems Engineering, such as complexity, reliability, and safety of different kinds of systems, creation, operation and maintenance of services, system-human communication, and management tasks done during system projects are addressed in the collection. This book is for people who are interested in the modern state of the Systems Engineering knowledge area and for systems engineers involved in different activities of the area. Some articles may be a valuable source for university lecturers and students; most of case studies can be directly used in Systems Engineering courses as illustrative materials.

\title{
How to reference
}

In order to correctly reference this scholarly work, feel free to copy and paste the following:

Sofia Lingegård, Tomohiko Sakao and Mattias Lindahl (2012). Integrated Product Service Engineering Factors Influencing Environmental Performance, Systems Engineering - Practice and Theory, Prof. Boris Cogan (Ed.), ISBN: 978-953-51-0322-6, InTech, Available from: http://www.intechopen.com/books/systemsengineering-practice-and-theory/integrated-product-service-engineering-factors-influencing-environmentalperformance

\section{INTECH}

open science | open minds

\section{InTech Europe}

University Campus STeP Ri

Slavka Krautzeka 83/A

51000 Rijeka, Croatia

Phone: +385 (51) 770447

Fax: +385 (51) 686166

www.intechopen.com

\section{InTech China}

Unit 405, Office Block, Hotel Equatorial Shanghai

No.65, Yan An Road (West), Shanghai, 200040, China 中国上海市延安西路65号上海国际贵都大饭店办公楼 405 单元

Phone: +86-21-62489820

Fax: +86-21-62489821 
(C) 2012 The Author(s). Licensee IntechOpen. This is an open access article distributed under the terms of the Creative Commons Attribution 3.0 License, which permits unrestricted use, distribution, and reproduction in any medium, provided the original work is properly cited. 